\title{
Risk Factors for Increased Delay between HIV Diagnosis and First Specialised Consultation among HIV-infected Patients in Guadeloupe: A Retrospective Cohort Study \\ N Elenga ${ }^{1}$, MT Georger-Sow ${ }^{2}$, T Messiaen $^{3}$, I Lamaury ${ }^{3}$, I Favre ${ }^{3}$, M Nacher $^{4}{ }^{4}$, G Beaucaire $^{3}$
}

\begin{abstract}
The variables influencing the interval between diagnosis and effective access to specialised care were studied in a cohort of 1542 human immunodeficiency virus (HIV)-positive patients in Guadeloupe between 1988 and 2009. A retrospective cohort study was conducted to determine the risk factors for increased delay between HIV diagnosis and first specialised consultation. Patients with a subsequent follow-up interruption were significantly more likely to have a delayed first consultation after HIV diagnosis. Ordinal logistic regression showed that male sex (OR:1.40[1.20-1.74], $\mathrm{p}=0.002)$, younger persons (OR: 1.50 [1.20-2.18], $\mathrm{p}=$ 0.001), patients in CDC category B (OR: 1.90 [1.30-2.70], $\mathrm{p}=0.002)$, patients diagnosed before 1997 (OR: 2.70[2.10-3.50], $\mathrm{p}=0.000), \mathrm{CD} 4$ count 200-499 (OR: 2.80 [2.20-3.50], $\mathrm{p}=$ 0.000) and CD4 count $>500(\mathrm{OR}: 4.30$ [3.20-6.10], $\mathrm{p}=0.000)$ were independently associated with greater delays between HIV diagnosis and the first specialised consultation. Focusing on the link between the private sector and specialised health care may shorten delays and improve care and follow-up.
\end{abstract}

Keywords: Delayed access to specialized care, Guadeloupe, HIV-infected patients, predictive factors

From: ${ }^{1}$ Service de Pédiatrie, Centre hospitalier de Cayenne " Andrée Rosemon », Rue des Flamboyants, BP 6006-97306 Cayenne cedex, Guyane française. ${ }^{2}$ Coordination Régionale VIH (COREVIH) Guadeloupe CHU de Pointe-à-Pitre / Abymes Bâtiment B Ancien Hôpital Ricou 2ème étage BP 46597159 Pointe-à-Pitre Cedex. ${ }^{3}$ Service des maladies infectieuses, Guadeloupe CHU de Pointe-à-Pitre / Abymes Bâtiment B Ancien Hôpital Ricou 2ème étage BP465 97159 Pointe-à-Pitre Cedex. ${ }^{4,5}$ Coordination Régionale VIH (COREVIH) Centre hospitalier de Cayenne «Andrée Rosemon», Centre d'Investigation Clinique Epidémiologie Clinique CIC EC Antilles Guyane CIE 802, Centre hospitalier de Cayenne "Andrée Rosemon», Rue des Flamboyants, BP 6006-97306 Cayenne cedex, Guyane française.

Correspondence: Dr N Elenga, Service de Pédiatrie, Centre hospitalier de Cayenne, Andrée Rosemon, Rue des Flamboyants, BP 6006-97306, Cayenne Cedex, Guyane Francaise. Fax: +594 594394 819, e-mail: elengafr@yahoo.fr 


\section{INTRODUCTION}

To improve the benefits of highly active antiretroviral therapy (HAART), a good health system should diagnose human immunodeficiency virus (HIV)-infected patients as early as possible, refer them to an HIV care facility, and maintain patient regular follow-up and care. The risk factors for late diagnosis (1) and follow-up interruption (2) have been described by a number of studies. Fewer studies, however, have studied the variables influencing the interval between the diagnosis and effective access to specialised care (3-6).

Guadeloupe is part of the French overseas territories, and has a large number of persons living with HIV/AIDS. HIV-positive patients followed at the University Hospital of Pointe-à-Pitre and Basse Terre hospitals since 1 January 1988 and at St. Martin Hospital since 1 January 1992 until 31 December 2009 were enrolled in the Guadeloupe section of the French Hospital Database for HIV (GFHDH). In Guadeloupe, here are frequent delays in HIV testing, notably among migrants, and the incidence of patients with interrupted followup is high.

\section{SUBJECTS AND METHODS}

To identify factors associated with delayed access to care, a retrospective study was conducted in Guadeloupe. All HIV-positive adult patients followed between 1 January 1988 and 31 December 2009 were enrolled in the French Hospital Database for HIV (FHDH). The FHDH is a national project that received approval in 1991. A trained research assistant uses standardized procedures to prospectively collect clinical, laboratory, and treatment data from medical records by using specialized French Ministry of Health software (Dossier MedicoEconomique Informatisé, version 2 [DMI2]). The cohort started in the late eighties and was 
approved by the commission nationale informatique et libertés (CNIL), and has led to several publications (7-9).

Time-independent variables, such as sex, nationality, and mode of acquisition of HIV, and time-dependent variables, such as age, CD4 and CD8 cell counts, HIV-1 viral loads, treatments, and clinical events, reported by the clinicians are routinely entered by trained clinical studies technicians. The identities of patients are encrypted before the data are sent to the Ministry of Health and the Institut National de la Recherche Médicale (INSERM), which centralises data from COREVIH (Regional Coordination of the Fight against HIV) facilities throughout France. The data were analysed using STATA 10.0 (STATA Corp., College Station, TX). The delay between the date of a positive HIV test and the first consultation in the hospital was calculated and categorised into $<1$ month, between 1 and 3 months, between 3 and 12 months, and $>12$ months. An ordinal logistic model with the categorised delays as the dependent variable was used to determine the independent variables that were related to the outcome.

\section{RESULTS}

A total of 1.542 patients were in the database. Of these, $4 \%$ were first seen in the hospital within 1 month, $23 \%$ were first seen between 1 and 3 months, $36 \%$ were first seen between 3 and 12 months, and $37 \%$ were first seen $>1$ year after diagnosis. Patients who later had at least one follow-up interruption (no consultation for $>1$ year) were more likely to have a delayed first consultation after HIV diagnosis than patients with no subsequent history of follow-up interruption ( $p=0.019)$. Table 1 shows male sex (OR:1.40[1.20-1.74], $p=0.002$ ), younger persons (OR: 1.50 [1.20-2.18], $p=0.001$ ), patients in CDC category B (OR: 1.90 [1.30-2.70], $p=0.002$ ), patients diagnosed before 1997 (OR: 2.70[2.10-3.50], $p=0.000$ ), 
CD4 count 200-499 (OR: 2.80 [2.20-3.50], $p=0.000)$ and CD4 count $>500(\mathrm{OR}: 4.30$ [3.206.10], $p=0.000$ ) were independently associated with greater delays between HIV diagnosis and the first specialised consultation.

\section{DISCUSSION}

Initial primary care presentation of patients with HIV infection generally occurs within days, months or years after acquisition of the virus. The portion of the delay in medical care attributable to the period between positive HIV test results and initiating primary care has not been well-defined. A reduction in this delay could help individuals to benefit from therapeutic advances. These benefits include antiretroviral therapy, prophylaxis of opportunistic infections, immunisations, and behavioural interventions. In our study, although a not negligible proportion of patients $(n=413[27 \%])$ made the initial linkage with medical care within three months, a substantial proportion (580 [37\%]) delayed for more than 1 year.

We found that the risk of delay was high between 1988 and 1996. This risk decreased from 1997 and 2005, but has not continued to show improvement since 2005. Samet et al. (10) reported a delay of 1 year or more before treatment for $40 \%$ of patients treated at two urban hospitals in New England. Nacher et al. (11) reported that 15\% of a sample of HIVinfected individuals in French Guiana delayed care for more than 1 year. Numerous forces influence the interval between the results of the HIV test and the first contact with an HIV specialist. These results suggest that some patients that do not have opportunistic infections are more likely to delay their access to care.

Drug users, because of the behavioural problems associated with addiction, may not be a suitable clientele for private practice and only are tested in the hospital, and thereby are immediate contact with HIV specialists. Patients may also have been more likely to have health insurance when consulting private practitioners. Finally, there was a link between the 
delay in accessing specialised care and the subsequent likelihood of follow-up interruption, thereby constituting an early warning sign that allows for interventions to improve follow-up. Improved coordination between hospitals and private practioners should lead to improved access to HIV care.

Since 1997, the management and prognosis of HIV infection have been transformed by powerful new classes of antiretroviral agents that reduce virus replication and allow the immune system to recover $(12,13)$. It remains to be seen whether these powerful therapies will encourage individuals to accept HIV testing and to receive care more promptly after a diagnosis of HIV infection. In our previous study, individuals on ART were seen to have a decreased risk of for follow-up interruption (2).

This study has limitations due to the limited number of explanatory variables, which need to be considered when interpreting the data. Some potential risk factors, such as education, HIV knowledge and awareness, religion affiliations, and employment status were not recorded.

\section{CONCLUSION}

Despite these limitations resulting from the retrospective nature of our study, this analysis offers the first Guadeloupean data on the problem of delayed medical care after diagnosis. However, most of our results are consistent with previous studies (11).

\section{List of abbreviations}

HAART: highly active antiretroviral therapy

HIV: human immunodeficiency virus

GFHDH: Guadeloupe section of the French Hospital Database for HIV

FHDH: French Hospital Database for HIV

INSERM: Institut National de la Recherche Médicale

COREVIH: comité de coordination de la lutte contre l'infection par le VIH 
ART: Antiretroviral therapy

DMI2 : Dossier Médico-Economique Informatisé, version 2

CNIL : commission nationale informatique et libertés

\section{ACKNOWLEDGEMENTS}

The authors would like to thank the members of the Guadeloupean HIV Cohort Study for data collection.

\section{AUTHORS’ NOTE}

MT is professor of epidemiology and public health at the University of the West Indies and French Guiana. BG is professor of infectious diseases at the University of the West Indies and French Guiana.

EN has made substantial contributions to conception and design, analysis and interpretation of data. MT, LI, FI and BG have made substantial contributions to acquisition of data. G-S M-T have made substantial contributions to acquisition of data and have been involved in drafting the manuscript and revising it critically for important intellectual content. NM has been involved in drafting the manuscript and revising it critically for important intellectual content and has given final approval of the version to be published.

The authors declare that they have no competing interests 


\section{REFERENCES}

1. Elenga N, Georger-Sow M-T, Nacher M. Risk Factors for Late Presentation for Care among HIV-Infected Patients in Guadeloupe: 1988-2009. J AIDS Clinic Res 2012; 3: 166.

2. Elenga N, Georger-Sow M-T, Messiaen T, Lamaury I, Favre I, Nacher M et al. Incidence and risk factors for follow-up interruption of HIV-infected patients in Guadeloupe. J AIDS Clinic Res; 3: 166.

3. Turner BJ, Cunningham WE, Duan N, Andersen RM, Shapiro MF, Bozzette SA et al. Delayed medical care after diagnosis in a US national probability sample of persons infected with human immunodeficiency virus. Arch Intern Med 2000; 160: 2614-22.

4. Gardner LI, Marks G, Metsch LR, Loughlin AM, O'Daniels C, del Rio C et al. Psychological and behavioral correlates of entering care for HIV infection: the Antiretroviral Treatment Access Study. AIDS Patient Care STDS 2007; 21: 418-25.

5. Girardi E, Aloisi MS, Arici C, Pezzotti P, Serraino D, Balzano R, et al. Behavioural Epidemiology Study Group. for the ICoNA Behavioural Epidemiology Study Group. Delayed presentation and late testing for HIV: demographic and behavioral risk factors in a multicenter study in Italy. J Acquir Immune Defic Syndr 2004; 36: 951-9.

6. Stein MD, Crystal S, Cunningham WE, Ananthanarayanan A, Andersen RM, Turner BJ et al. Delays in seeking HIV care due to competing caregiver responsibilities. Am J Public Health 2000; 90: 1138-40.

7. Kousignian I, Abgrall S, Grabar S, Mahamat A, Teicher E, Rouveix E et al. Clinical Epidemiology Group of the French Hospital Database on HIV. Maintaining antiretroviral therapy reduces the risk of AIDS-defining events in patients with uncontrolled viral replication and profound immunodeficiency. Clin Infect Dis 2008; 46: $296-304$. 
8. Grabar S, Selinger-Leneman H, Abgrall S, Pialoux G, Weiss L, Costagliola D. Prevalence and comparative characteristics of long-term nonprogressors and HIV controller patients in the French Hospital Database on HIV.AIDS. 2009; 23: 1163-9.

9. Potard V, Weiss L, Lamontagne F, Rouveix E, Beck-Wirth G, Drogoul-Vey MP et al. Trends in post-infection CD4 cell counts and plasma HIV-1 RNA levels in HIV-1infected patients in France between 1997 and 2005.J Acquir Immune Defic Syndr 2009; 52: 422-6.

10. Samet JH, Freedberg KA, Stein MD, Lewis R, Savetsky J, Sullivan L et al. Trillion virion delay: time from testing positive for HIV to presentation for primary care. Arch Intern Med 1998; 158: 734-40.

11. Nacher M, Adriouch L, Adenis A, Hanf M, Van Melle A, Parriault MC et al. Risk factors for delayed access to specialised care in French Guiana. Am J Trop Med Hyg 2011; 84: 806-7.

12. Palella FJ Jr, Delaney KM, Moorman AC, Loveless MO, Fuhrer J, Satten GA, et al. Declining morbidity and mortality among patients with advanced human immunodeficiency virus infection. HIV Outpatient Study Investigators. N Engl J Med 1998; 338: 853-60.

13. Moore RD, Chaisson RE. Natural history of HIV infection in the era of combination antiretroviral therapy. AIDS 1999; 13: 1933-42. 
Table: Risk factors for increased delay between HIV diagnosis and first specialised consultation

\begin{tabular}{|c|c|c|c|}
\hline Variables & Crude OR (95\% CI) & $\mathbf{p}$ & Adjusted OR* (95\% CI) \\
\hline \multicolumn{4}{|l|}{ Age } \\
\hline$\leq 30$ & $1.45(1.23-1.71)$ & 0.000 & $1.10(0.54-1.40)$ \\
\hline $30-40$ & $1.36(1.17-1.59)$ & 0.000 & $1.50(1.20-2.18)$ \\
\hline$>40$ & 1 & & 1 \\
\hline \multicolumn{4}{|l|}{ Gender } \\
\hline Female & 1 & & 1 \\
\hline Male & $1.14(0.55-1.4)$ & 0.16 & $1.40(1.20-1.74)$ \\
\hline \multicolumn{4}{|c|}{ HIV diagnosis period } \\
\hline 2006-2009 & 1 & & 1 \\
\hline $1997-2005$ & $1.59(1.06-2.38)$ & 0.026 & $1.20(0.94-1.60)$ \\
\hline $1988-1996$ & $2.87(1.92-4.29)$ & 0.000 & $2.7(2.10-3.50)$ \\
\hline \multicolumn{4}{|c|}{ Initial CD4 cell count } \\
\hline$<200$ & 1 & & 1 \\
\hline $200-499$ & $\begin{array}{l}2.5(2.03-3.13) \\
3.75(2.8-5.10)\end{array}$ & $\begin{array}{c}0.000 \\
0.000\end{array}$ & $2.8(2.20-3.50)$ \\
\hline$\geq \mathbf{5 0 0}$ & .000 & & $4.30(3.20-6.10)$ \\
\hline \multicolumn{4}{|l|}{ Nationality } \\
\hline French & 1 & & 1 \\
\hline Haiti & $3.10(0.92-10.2)$ & 0.068 & $1.40(0.40-5.30)$ \\
\hline Others & $2.30(1.10-4.7)$ & 0.03 & $0.98(0.45-2.10)$ \\
\hline \multicolumn{4}{|c|}{ CDC category } \\
\hline $\mathrm{A}$ & $0.98(0.82-1.20)$ & 0.8 & $1.20(0.90-1.60)$ \\
\hline $\mathrm{B}$ & $1.54(1.20-2.00)$ & 0.001 & $1.90(1.30-2.7)$ \\
\hline $\mathrm{C}$ & 1 & & 1 \\
\hline \multicolumn{4}{|c|}{ Known drug use/addiction } \\
\hline no & 1 & & 1 \\
\hline yes & $0.26(0.12-0.56)$ & 0.001 & $0.42(0.20-1.02)$ \\
\hline
\end{tabular}

* Obtained using an ordinal logistic regression model including the above covariates. CI confidence interval 